\title{
Green Supply Chain Network Design with Economies of Scale and Environmental Concerns
}

\author{
Dezhi Zhang, ${ }^{1}$ Fangzi Zou, ${ }^{1}$ Shuangyan Li, ${ }^{2}$ and Lingyun $\mathrm{Zhou}^{3}$ \\ ${ }^{1}$ School of Traffic \& Transportation Engineering, Central South University, Changsha, Hunan 410075, China \\ ${ }^{2}$ School of Transportation and Logistics, Central South University of Forestry and Technology, Changsha, Hunan 410004, China \\ ${ }^{3}$ School of Management Engineering, Huaiyin Institute of Technology, Huaian, Jiangsu 223001, China \\ Correspondence should be addressed to Shuangyan Li; lishuangyan585@163.com
}

Received 19 February 2017; Revised 23 March 2017; Accepted 3 April 2017; Published 20 April 2017

Academic Editor: Zhi-Chun Li

Copyright (C) 2017 Dezhi Zhang et al. This is an open access article distributed under the Creative Commons Attribution License, which permits unrestricted use, distribution, and reproduction in any medium, provided the original work is properly cited.

\begin{abstract}
This study considers a design problem in the supply chain network of an assembly manufacturing enterprise with economies of scale and environmental concerns. The study aims to obtain a rational tradeoff between environmental influence and total cost. A mixed-integer nonlinear programming model is developed to determine the optimal location and size of regional distribution centers (RDCs) and the investment of environmental facilities considering the effects of economies of scale and $\mathrm{CO}_{2}$ emission taxes. Numerical examples are provided to illustrate the applications of the proposed model. Moreover, comparative analysis of the related key parameters is conducted (i.e., carbon emission tax, logistics demand of customers, and economies of scale of RDC), to explore the corresponding effects on the network design of a green supply chain. Moreover, the proposed model is applied in an actual case-network design of a supply chain of an electric meter company in China. Findings show that (i) the optimal location of RDCs is affected by the demand of customers and the level of economies of scale and that (ii) the introduction of $\mathrm{CO}_{2}$ emission taxes will change the structure of a supply chain network, which will decrease $\mathrm{CO}_{2}$ emissions per unit shipment.
\end{abstract}

\section{Introduction}

The current problem regarding supply chains has attracted the attention of several production companies due to the increasing use of e-commerce. Operations in supply chain and logistics are significant economic activities for competitive businesses. The growing volume of activities generated by multimodal transportation benefits not only the growth of the economy and globalization but also the environment. Generally, transportation is viewed as a major contributor to climate change and global warming, which is caused by air pollution and greenhouse gas emission. Approximately 5.5\% of global greenhouse gas emissions are generated by freight transportation [1]. It is, therefore, very important and urgent to create an environmentally sustainable supply chain and green logistics system.

Supply chain management (SCM) is a process that involves efficient planning, implementation, and control of supply chain operations [2]. Traditionally, design models of a supply chain are focused on minimizing fixed and operating costs without considering carbon emissions. Sadjady and Davoudpour [3] formulated a two-echelon supply chain network design problem as a mixed-integer programming model and solved it efficiently using Lagrangian-based heuristic algorithm. Wang et al. [4] addressed the hierarchical structure of logistics network optimization problem using a fuzzy-based customer clustering approach. They used a case study in Anshun, China, to evaluate the effectiveness of the proposed approach. Moreover, Wang et al. [5] investigated a two-echelon logistics distribution network design optimization model that is solved using a hybrid algorithm embedded with particle swarm optimization and genetic algorithm (GA). Sabzevari Zadeh et al. [6] and González et al. [7] presented a mixed-integer nonlinear programming (MINLP) model and a mixed-integer linear programming (MILP) to design a dynamic multicommodity inventory and facility location problem in a supply chain network. Prakash et al. [8] proposed a knowledge-based GA for the network 
optimization of supply chain. A Monte Carlo optimization approach combined with the sample average approximation scheme and the Lagrangian relaxation-based approach was proposed to address the integrated facility location and supplier selection decisions for the design of a supply chain network [9]. Other related studies were conducted by [10-12].

Distribution centers (DCs) have recently been established in cities for the rapid distribution of freights. Thus, the number of studies on SCM regarding DCs and economies of scale has been increasing. Tsao [13] used a continuous approximation method for formulating the model and then decided the location of DCs and the manner in which retail stores were assigned to DCs and the joint replenishment cycle time at DCs. Qin [14] used planning methods and models for presenting the planning of the processes, functional area layout, facilities and equipment selection, and cargo storage. Gorman and Ball [15] developed a simple heuristic to defer deliveries, eliminating several deliveries and improving its economics. Baumgartner et al. [16] considered a three-echelon, multiproduct supply chain design model with economies of scale in transport and warehousing. Saranwong and Likasiri [17] attempted to find the best locations for DCs and production distributions through a bilevel programming model. With regard to economies of scale, optimal solution approaches have been developed [18], which relied on Lagrangian relaxation. Fleischmann [19] presented a general multiproduct distribution planning model for designing distribution systems with transport economies of scale. Li et al. [20] proposed a 0 -1 integer programming (IP) problem and solved it by an implicit enumeration heuristic solution algorithm. The results show that the average construction cost per unit area for a logistics park decreases as the size of DCs increases.

Multimodal transportation provides more cost-effective solutions than the single-mode transportation. Beresford et al. [21] focused on the available multimodal transport route variations for iron ore shipment problems and used an established cost model as a framework. Islam et al. [22] discussed supply chain integration and the implications for intermediaries and shippers or manufacturers in multimodal freight transport systems. Vilko and Hallikas [23] mapped the process and the structure and presented a new framework for categorizing the risks of driver factors to assess overall impact on supply chain performance. Xie et al. [24] considered three transport modes to minimize the total cost for infrastructure, feedstock harvesting, biofuel production, and transportation. Sitek and Wikarek [25] provided a mathematical model of multilevel cost optimization in the form of MILP in multimodal logistics. Two environments of IP and constraint logic programming were integrated [26], which is solved by a hybrid approach for supply chain optimization.

Another relevant research is the design problem for a green supply chain, which obtained significant attention from researchers. This problem is usually modeled as a single objective. For example, Tognetti et al. [27] studied the interplay between emissions and costs of the supply chain contingent upon the production volume allocation and the energy mix. Elhedhli and Merrick [28] used a Lagrangian relaxation for decomposing the green supply chain problem into a capacitated facility location problem with a single source and a concave knapsack problem. Wang et al. [29] analyzed the manner in which carbon emissions affect the selection of transport modes and social welfare using a two-stage Stackelberg gaming model. McKinnon and Piecyk [30] examined various methods of carbon auditing of road freight transport, which could affect the policy-making process and the decisions of industry stakeholders. Recently, a multiobjective optimization of the network design of a green supply chain has been considered by an increasing number of researchers. Wang et al. [31] proposed a multiobjective optimization model that captured the tradeoff between the total cost and environmental influence of a supply chain. Harris et al. [32] solved the capacitated facility location problem based on a multiobjective algorithm using the Lagrangian relaxation, in which the financial cost and $\mathrm{CO}_{2}$ emissions are considered. Then, they proposed a hybrid multiobjective approach for capacitating a facility location with flexible store allocation for green logistics modeling [33]. Soysal et al. [34] developed a multiobjective linear programming model for an international beef supply chain network considering emission and solved this model using the $\mathcal{\varepsilon}$-constraint method. Moreover, researchers have attempted to extend the model by incorporating various factors. For example, a heuristic solution algorithm was presented to solve a bilevel formulation model and determine the optimal location and size of logistics parks considering $\mathrm{CO}_{2}$ emission taxes [35]. Benjaafar et al. [36] showed the manner in which carbon emission parameters with various decision variables and traditional models could be modified to support decisionmaking for both cost and carbon footprint. Hoen et al. [37] considered the emission cost and constraint alternatively and showed that the emission cost was only a small part of the total cost and not likely to result in significant changes in transport modes. Furthermore, Hoen et al. [38, 39] addressed effect of carbon emission regulations on transport mode selection under stochastic demand by a carbon emission measurement methodology. Sheng et al. [40] developed an integrated model to investigate the economic and environmental effects of a unilateral maritime emission regulation.

To the best of our knowledge, existing related studies on the network design of supply chains considering the economies of scale and the environment are still scarce. The present study aims to fill this gap by optimizing the location and size of regional DCs (RDCs), as well as the investment of environmental facilities.

We develop a MINLP model of a network problem for a green supply chain. This model aims to minimize total logistics cost, which covers the fixed cost of RDCs, environmental facility and operating costs, and $\mathrm{CO}_{2}$ emission costs. The contributions of this study are as follows.

(1) A MINLP model of the network design problem for a supply chain is presented, which considers multimodal transportation, $\mathrm{CO}_{2}$ emissions taxes, and investment of environmental facility.

(2) The economies of scale of RDCs are considered in the network design of the supply chain.

(3) Managerial insights and pieces of advice regarding the network design of the green supply chain for assembly manufacturing enterprises are provided. 


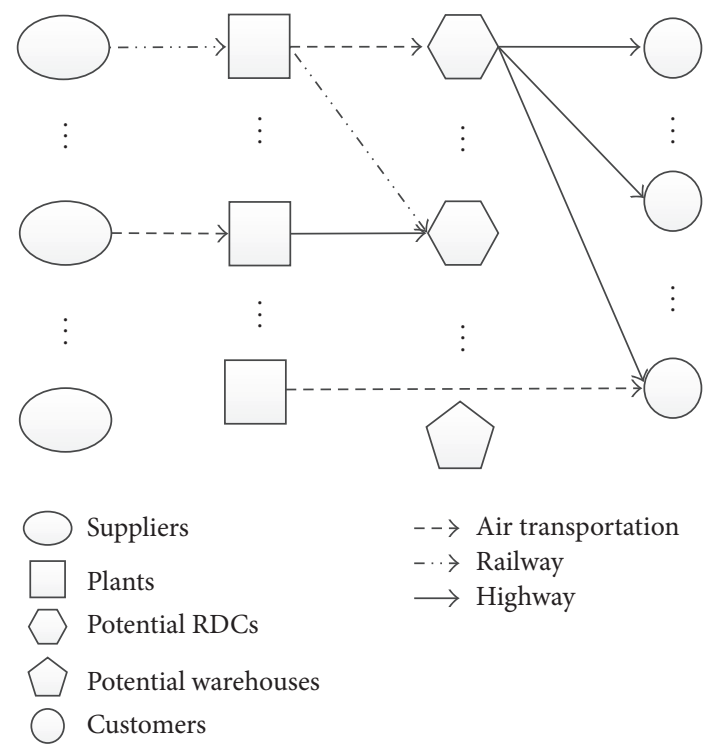

FIGURE 1: Representation of the four-level supply chain network.

The remainder of this paper is as follows. We discuss our problem thoroughly and present an MINLP model for a four-level network design in the next section. In Section 2, we conduct small-case numerical experiments to characterize the optimal solutions and their sensitivities to various input parameters. Then, the MINLP model is applied in a real-life case of a supply chain of an electric meter company in China, and managerial insights are introduced in Section 4. Finally, conclusions are presented in Section 5.

\section{Problem Description and Modeling}

We assume that a "product" can represent either a specific product or product category. In this study, the planning period is accomplished after one week. In addition, the two different types transfer logistics nodes are RDCs and rented warehouses, respectively. A high environmental investment means a sophisticated facility or technology installed in the plants, which results in a lower unit $\mathrm{CO}_{2}$ emission level, so as to obtain the expected $\mathrm{CO}_{2}$ emission reduction target.

Consider a four-level supply chain network, $G=(N, S)$, where $N=\{A, B, C, D\}$ and $S$ are the sets of nodes and arcs, respectively. The node set comprises four subsets: $A, B, C$, and $D$. A represents the nodes where suppliers connect or start; $B$ represents the nodes where plant locations connect; and $C$ represents the nodes where potential RDCs or warehouses connect. We use $C^{1}$ and $C^{2}$ to represent the node sets of potential RDCs and warehouses, respectively. $D$ represents the nodes where customers connect or end. The arc set comprises six subsets: $A B_{a}, B C_{a}^{1}, C^{1} D_{a}, B D_{a}, B C_{a}^{2}$, and $C^{2} D_{a}$. These subsets represent set of arcs between suppliers and plant locations, plant locations and RDCs, RDCs and customers, plant locations and customers, plant locations and rented warehouses, and rented warehouses and customers, respectively. Multiple alternative transport modes are present in each arc, such as highways, railways, and air transportation (see Figure 1).

To design a green supply chain network, the following key questions should be solved: (1) When should decisionmakers arrange RDCs from a potential RDCs set, select its size according to economies of scales, or rent warehouses from an outsider? (2) Which type of facility or technology in the plant locations should be purchased to decrease $\mathrm{CO}_{2}$ emissions? (3) How should the combinations of optimal transport modes be selected to complete the transport tasks among an entire supply chain network?

The parameters and the decision variables used to formulate the model are shown in Notations.

The following economic and environmental object functions are considered simultaneously in this study:

$$
\begin{aligned}
& \text { Minimize } \quad W_{1} \\
& \qquad \sum_{i \in B} \alpha_{i} c_{i}^{f}+\sum_{i \in C^{1}}\left(c_{i}+c_{i}^{u}\left(y_{i}\right)^{\theta}\right) \beta_{i} \\
& +\sum_{m \in M_{i, j}} \sum_{i \in C^{1}} x_{i, j}^{m} c_{i}^{v} \beta_{i} \\
& +\sum_{m \in M_{i, j}} \sum_{(i, j) \in S} c_{i, j}^{m} d_{i, j}^{m} x_{i, j}^{m} \\
& +\sum_{m \in M_{i, j}} \sum_{i \in C^{2}} c_{i}^{m} x_{i, j}^{m} \beta_{i} .
\end{aligned}
$$

Equation (1) represents the minimizing financial cost $W_{1}$, which includes five parts. The first term in the right side of (1) is the total cost of environmental protection investment. The second is the total cost for opening new RDCs, including the fixed and construction costs. The third is the variable cost for handling products. The fourth is the total transportation cost. The last is the total transfer cost for the transport of products at the rented warehouses.

$$
\text { Minimize } W_{2}=\left(\sum_{m \in M_{i, j}} \sum_{(i, j) \in S} e_{i, j}^{m} d_{i, j}^{m} x_{i, j}^{m}+\sum_{m \in M_{i, j}} \sum_{i \in B}\left(1-\alpha_{i} r_{i}\right) e_{i}^{h} x_{i, j}^{m}\right) \cdot z .
$$

Equation (2) represents the reduction of the total $\mathrm{CO}_{2}$ emission cost $W_{2}$, which includes two parts. The first term in the right side of (1) is the $\mathrm{CO}_{2}$ emission produced from product transport, whereas the second is the $\mathrm{CO}_{2}$ emission 
TABLE 1: Unit transport cost and $\mathrm{CO}_{2}$ emissions.

\begin{tabular}{lccc}
\hline & Highway & Railway & Air transportation \\
\hline Unit transport cost $(\$ / \mathrm{t}-\mathrm{km})$ & 0.42 & 0.35 & 0.50 \\
Unit $\mathrm{CO}_{2}$ emissions $(\mathrm{kg} / \mathrm{t}-\mathrm{km})$ & 0.14 & 0.08 & 0.06 \\
\hline
\end{tabular}

produced from environmental facilities or technologies while handling the product in plant.

$$
\begin{aligned}
& \min T C \\
& =\sum_{i \in B} \alpha_{i} c_{i}^{f}+\sum_{i \in C^{1}}\left(c_{i}+c_{i}^{u}\left(y_{i}\right)^{\theta}\right) \beta_{i}+\sum_{m \in M_{i, j}} \sum_{i \in C^{1}} x_{i, j}^{m} c_{i}^{v} \beta_{i} \\
& +\sum_{m \in M_{i, j}} \sum_{i, j) \in S} c_{i, j}^{m} d_{i, j}^{m} x_{i, j}^{m}+\sum_{m \in M_{i, j}} \sum_{i \in C^{2}} c_{i}^{m} x_{i, j}^{m} \beta_{i} \\
& +\left(\sum_{m \in M_{i, j}} \sum_{(i, j) \in S} e_{i, j}^{m} d_{i, j}^{m} x_{i, j}^{m}+\sum_{m \in M_{i, j}} \sum_{i \in B}\left(1-\alpha_{i} r_{i}\right) e_{i}^{h} x_{i, j}^{m}\right) \\
& \cdot z \\
& \text { s.t. } \sum_{m \in M_{i, j}} \sum_{j \in B} x_{i, j}^{m} \leq s_{i} \quad i \in A \\
& \sum_{m \in M_{i, j}} \sum_{i \in A} x_{i, j}^{m}=\sum_{m \in M_{i, j}} \sum_{i \in C} x_{j, i}^{m}+\sum_{t=1}^{L} \sum_{m \in M_{i, j}} \sum_{i \in D} x_{j, i}^{m} \quad j \in B \\
& \sum_{m \in M_{i, j}} \sum_{i \in B} x_{i, j}^{m}=\sum_{m \in M_{i, j}} \sum_{i \in D} x_{j, i}^{m} \quad j \in C \\
& \sum_{m \in M_{i, j}} \sum_{j \in C} x_{j, i}^{m}+\sum_{m \in M_{i, j}} \sum_{j \in B} x_{j, i}^{m} \geq d_{i} \quad i \in D \\
& \sum_{m \in M_{i, j}} \sum_{j \in B}^{J} \operatorname{cap}_{i}^{c} x_{j, i}^{m} \leq y_{i} \beta_{i} \quad i \in C^{1} \\
& \sum_{m \in M_{i, j}} \sum_{j \in B}^{J} x_{j, i}^{m} \leq \operatorname{cap}_{i}^{w} \beta_{i} \quad i \in C^{2} \\
& y_{i} \in M \\
& x_{i, j}^{m} \geq 0 \\
& \beta_{i}, \alpha_{i} \in\{0,1\} .
\end{aligned}
$$

The objective function in (3) represents the minimal total cost of the entire network while satisfying all the demands of customers, which includes the total financial cost $W_{1}$ and total $\mathrm{CO}_{2}$ emission cost $W_{2}$.

Constraint (4) forces capacity restriction on suppliers. Constraint (5) balances the flow of goods in and out of plant locations. Constraint (6) balances the flow of goods in and out of RDCs. Constraint (7) ensures that the demand of customers should be satisfied. Constraint (8) states that the total processing requirement of all products handled in RDCs should not exceed RDC capacity when they are opened $\left(\beta_{i}=1\right)$ and ensures that $x_{i, j}^{m}=0$, while $\beta_{i}=0$. Constraint (9) ensures that the capacity of rented warehouse is not exceeded. Constraint (10) shows the alternative size of potential RDCs. Constraints (11) and (12) define the decision variable as binary.
TABLE 2: Capacity of five suppliers.

\begin{tabular}{cccccc}
\hline & S1 & S2 & S3 & S4 & S5 \\
\hline Capacity of suppliers $(t)$ & 1430 & 1500 & 1580 & 1460 & 1550 \\
\hline
\end{tabular}

TABle 3: Distance from suppliers to plants by different transport modes $(\mathrm{km})$.

\begin{tabular}{lccc}
\hline Supplies & \multicolumn{3}{c}{ Plants } \\
& P1 & P2 & P3 \\
\hline S1 & $780 / 890 / 690$ & $790 / 850 / 700$ & $820 / 880 / 680$ \\
S2 & $720 / 850 / 600$ & $720 / 790 / 650$ & $710 / 770 / 630$ \\
S3 & $920 / 900 / 810$ & $920 / 980 / 820$ & $980 / 1050 / 830$ \\
S4 & $700 / 850 / 620$ & $710 / 760 / 630$ & $720 / 850 / 610$ \\
S5 & $790 / 900 / 630$ & $850 / 940 / 650$ & $770 / 850 / 610$ \\
\hline
\end{tabular}

Note: the three values of each cell of distance in Table 3 represent the three different distance values by road, train, and air transportation, respectively (e.g., 780/890/690 means that the distance from S1 to P1 by road, train, and air transportation transport modes is 780,890 , and $690 \mathrm{~km}$, resp.).

\section{Numerical Experiments}

In this section, we consider a four-level supply chain network, which illustrates the above optimal supply chain network design model. A relatively small problem with five suppliers, three plant locations, five potential RDCs, and two alternative warehouses, twelve customers, and one product is presented in this example, wherein sufficient number of RDCs or warehouses satisfy all customers' demand. Customers are assigned to the selected RDCs or warehouses considering the corresponding capacities. Each arc is associated with a different transport mode, which has different cost and unit product cost of $\mathrm{CO}_{2}$ emission. The unit transport cost and $\mathrm{CO}_{2}$ emission of different transport modes are shown as Table 1 .

The unit $\mathrm{CO}_{2}$ emission tax is $0.12 \$ / \mathrm{kg}$. The economies of scale parameter are set to $\theta=0.8$. Four different alternative sizes are available for each potential RDCs (i.e., 600, 800, 1000 , and $1200 \mathrm{~m}^{2}$, resp.) (Zhang et al. [35]). Other relevant parameters are shown in Tables $2-8$.

We solve the optimal transportation mode based on the above data using Lingo11.0. In the optional configuration, the product flows through different modes between nodes and relative costs. The result is shown in Figure 2.

The optimal configuration illustrates that three suppliers in nodes 2, 4, and 5 are selected to supply products to three plant locations through land and air transportation. Environmental protection equipment is built in nodes 2 and 3. The facility has high environmental investment, but its $\mathrm{CO}_{2}$ emission is low. We compare the transferring cost in warehouses and the cost for setting up RDCs while 
TABLE 4: Relevant parameters for the three plants.

\begin{tabular}{lccc}
\hline Plants & Environmental facility cost $(\$)$ & Ratio of lowered $\mathrm{CO}_{2}$ emission & $\mathrm{CO}_{2}$ emissions from handling a product unit $(\mathrm{kg})$ \\
\hline P1 & 12000 & 0.38 & 28 \\
P2 & 9500 & 0.32 & 22 \\
P3 & 10500 & 0.35 & 25 \\
\hline
\end{tabular}

TABLE 5: Distance from plants to potential RDCs by different transport modes $(\mathrm{km})$.

\begin{tabular}{|c|c|c|c|c|c|c|c|}
\hline \multirow{2}{*}{ Plants } & \multicolumn{7}{|c|}{ RDCs and warehouses } \\
\hline & D1 & $\mathrm{D} 2$ & D3 & $\mathrm{D} 4$ & D5 & W6 & W7 \\
\hline $\mathrm{P} 1$ & $380 / 440 / 320$ & $320 / 460 / 280$ & $340 / 470 / 290$ & $340 / 480 / 300$ & $310 / 460 / 260$ & $310 / 440 / 290$ & $320 / 460 / 300$ \\
\hline $\mathrm{P} 2$ & $440 / 540 / 400$ & $460 / 550 / 410$ & $500 / 640 / 440$ & $530 / 670 / 500$ & $430 / 580 / 400$ & $380 / 550 / 350$ & $600 / 740 / 560$ \\
\hline P3 & $280 / 450 / 250$ & $550 / 690 / 500$ & $480 / 660 / 400$ & $480 / 640 / 450$ & $350 / 500 / 300$ & $610 / 760 / 570$ & $460 / 420 / 420$ \\
\hline
\end{tabular}

Note: the three values of each cell of distance in Table 5 represent the three different distance values by road, train, and air transportation, respectively (e.g., $380 / 440 / 320$ means that the distance from P1 to D1 by road, train, and air transportation transport modes is 380,440 , and $320 \mathrm{~km}$, resp.).

considering both capital and demand. Finally, two RDCs with a size of $1200 \mathrm{~m}^{2}$ are set up, respectively, at nodes 1 and 5. Only one warehouse is selected at node 6 . Three transport modes are between plant locations and RDCs and warehouse. Given the distance between RDCs and warehouses to customers, roads are mainly used for transporting products to meet the demands of customers. A special scenario is shown during air transport from the plant to the customers. In this example, the tradeoff between the total cost and $\mathrm{CO}_{2}$ emission can be considered significantly when designing the green supply chain network for multimodal transportation.

3.1. Effects of Different Ratios of Carbon Tax on the Network Design of the Green Supply Chain. We vary the ratio of the carbon tax for comparing the total cost, selection of RDCs and warehouses, and purchasing equipment in plant location to test the behavior of the algorithm of the optimal network design. The results are illustrated in Table 9. The test statistics present several insights about the formulation and solution algorithm. (1) The total cost is directly proportional to the ratio of carbon tax. With the improvement of the ratio of carbon tax, the total cost increases. (2) Carbon tax ratio has influence on RDC selection. As the ratio of carbon tax is higher, the transportation plan will be adjusted to decrease $\mathrm{CO}_{2}$ emission. More and more products will be transported intensively; hence, the number of RDCs will be few. (3) The amount of purchasing environmental protection equipment in plant locations increases as the range of the ratio of carbon tax increases from 0.005 to 0.4 . Therefore, the increasing carbon tax ratio has a direct effect on improving environmental concerns.

First, with the increase of the carbon tax ratio, more units of environmental protection equipment are purchased in plant locations to reduce $\mathrm{CO}_{2}$ emission while handling products. However, the transportation costs will increase. Moreover, the total cost increases because the increase in transportation cost is more than the reduced cost. Then, the selection of RDCs changes as the range of carbon tax ratio increases from 0.005 to 0.4. Many reasons, such as cost of $\mathrm{CO}_{2}$ emission, customers' demand, and capacity of potential RDCs, can lead to product flow relocation on the road. Thus, the changing value of carbon tax ratio can impact the selection of RDCs. Finally, the best solution is not to buy environmental protection equipment in three plant locations when the ratio of carbon tax is 0.08 and less, wherein the environmental investment is higher than the reduced cost of $\mathrm{CO}_{2}$ emission. Otherwise, with the increasing carbon tax, the best solution is to buy environmental protection equipment and change the plan of RDC location. The results show that carbon tax incentives can improve the performance of the green supply chain economically and environmentally.

3.2. Effects of Different Demands of Customers on the Network Design of the Green Supply Chain. We vary the demand of customers to test the solution algorithm. A series of results are presented in Table 10 . We clearly observe the feasible solutions when customers demand for products increased by $40 \%$ and above. Customers' demands do not violate the capacity of the suppliers. Supplier chain working with a larger scope of suppliers' selection can outstrip the total demands. This situation is meaningful especially when customers demand increases temporarily. To protect corporate profits from insufficient supply and meeting temporary customers' product demands, companies will determine an appropriate number of suppliers and delivery products during unit time according to the actual situation. When customers' demand is changing, the selection of plant locations and the environmental investment can be different. Furthermore, Figure 3 shows that as the demand increases, there is a large drop in both the total cost and environmental investment results. When the demand decreases by $15 \%$, only two RDCs are chosen and none of the warehouse is rented. With the demand increasing, more and more RDCs are chosen, and its size becomes larger. When the demand increases by $35 \%$, comparing the cost of operating RDCs and renting warehouses, both warehouses at nodes 6 and 7 are rented to meet customers' demand. Though the total cost is increasing, the change ratio of cost is decreasing. Figure 3 presents the relationship between the total cost and its change ratio with changes in different customer demands. The economies of scale can explain this phenomenon in the operation stage. 


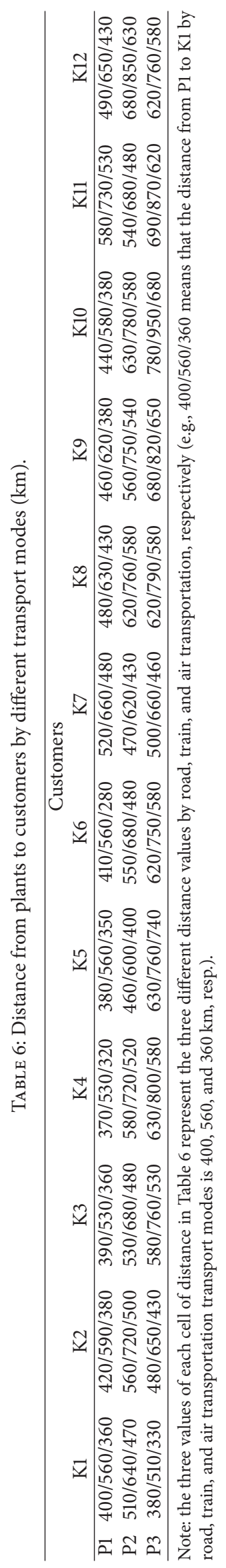


TABLE 7: Relevant parameters for the five potential RDCs and two warehouses.

\begin{tabular}{|c|c|c|c|c|c|c|}
\hline $\begin{array}{l}\text { RDCs/ } \\
\text { warehouses }\end{array}$ & $\begin{array}{l}\text { Fixed } \\
\text { cost }(\$)\end{array}$ & $\begin{array}{c}\text { Variable cost per } \\
\text { product unit } \\
(\$ / \mathrm{t})\end{array}$ & $\begin{array}{l}\text { Unit construction cost } \\
\qquad\left(\$ / \mathrm{m}^{2}\right)\end{array}$ & $\begin{array}{c}\text { Capacity consumed } \\
\text { by handling a product } \\
\text { unit }\left(\mathrm{m}^{2} / \mathrm{t}\right)\end{array}$ & $\begin{array}{l}\text { Transfer cost per } \\
\text { product unit }(\$ / t)\end{array}$ & $\begin{array}{l}\text { Capacity of rented } \\
\text { warehouses (t) }\end{array}$ \\
\hline D1 & 2200 & 3.5 & 15 & 1.7 & - & - \\
\hline D2 & 2300 & 3.4 & 16 & 1.6 & - & - \\
\hline D3 & 2500 & 3.0 & 19 & 1.5 & - & - \\
\hline D4 & 2400 & 3.1 & 17 & 1.5 & - & - \\
\hline D5 & 2300 & 3.3 & 18 & 1.7 & - & - \\
\hline W6 & - & - & - & - & 12 & 1200 \\
\hline W7 & - & - & - & - & 14 & 1300 \\
\hline
\end{tabular}

Five suppliers

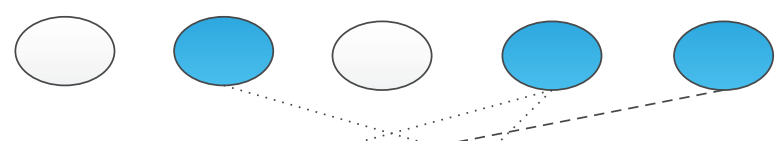

Three plants
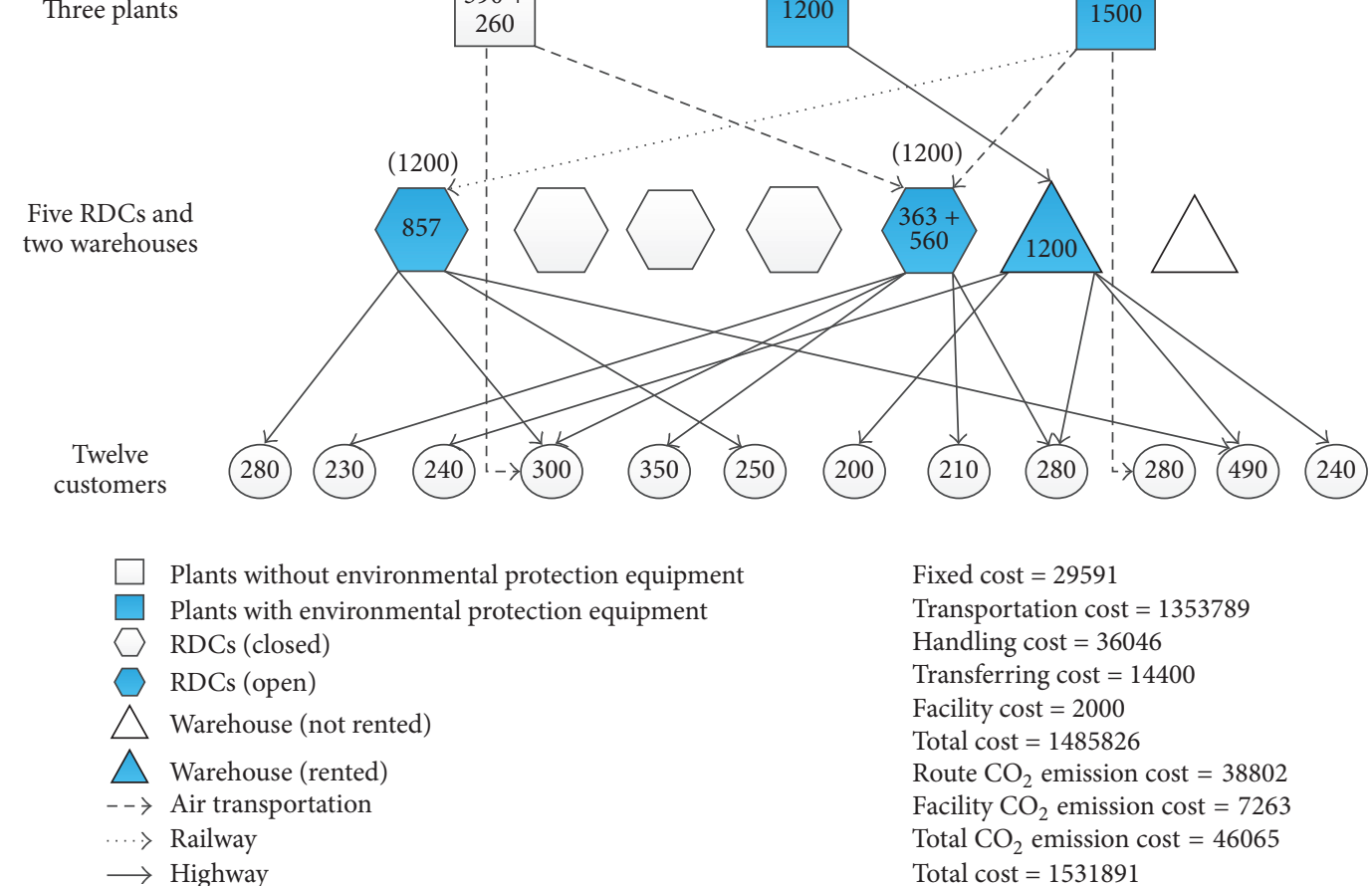

Fixed cost $=29591$

Transportation cost $=1353789$

Handling cost $=36046$

Transferring cost $=14400$

Facility cost $=2000$

Total cost $=1485826$

Route $\mathrm{CO}_{2}$ emission cost $=38802$

Facility $\mathrm{CO}_{2}$ emission cost $=7263$

Total $\mathrm{CO}_{2}$ emission cost $=46065$

Total cost $=1531891$

FIGURE 2: Supply chain network structure and related decision variables for the case.

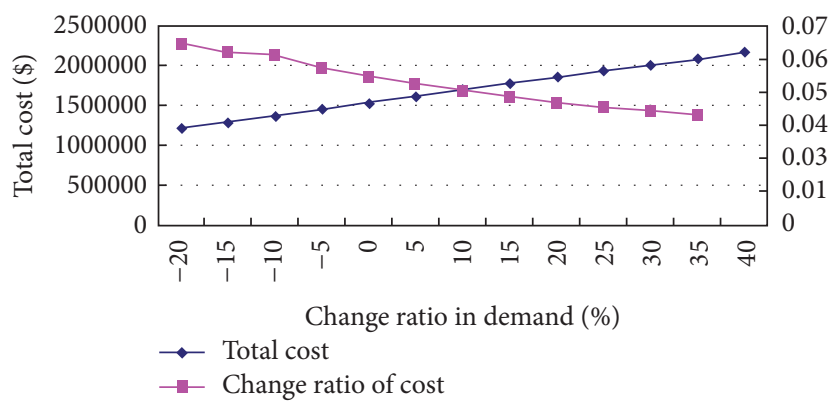

Figure 3: Total cost and its change ratio of different demands.
3.3. Effects of the Parameter Value of Economies of Scale on the Network Design of the Green Supply Chain. Other parameters remain unchanged to test the scaling parameters of the optimal network design. Installing additional capacity adds to the cost by examining a series of economies of scale factors, which modify the economy of scale parameter in analyzing its effect on the optimal number and size of RDCs. The results are shown in Table 11.

The warehouse located at node 6 is selected for the entire time in Figure 4. The size of RDCs is drastically different from the original case. When the economies of scale parameter $\theta$ 


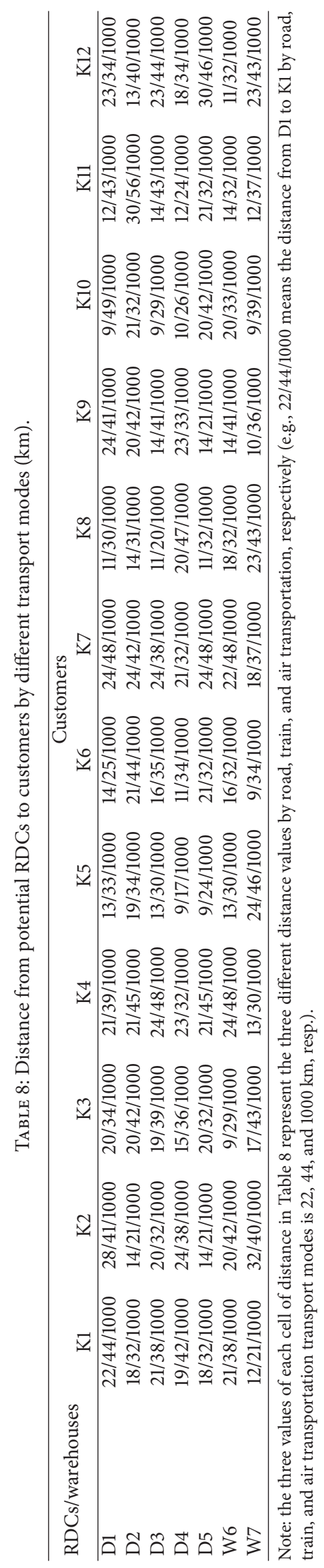


TABLE 9: Comparison based on different ratios of carbon tax.

\begin{tabular}{lccr}
\hline $\mathrm{CO}_{2}$ emission tax $(\$ / \mathrm{kg})$ & Total cost $(\$)$ & DC (Location size) & Environmental facility \\
\hline 0.05 & 1499815 & D1 (600), D2 (600), D5 (1200), W6 (1200) & - \\
0.08 & 1515098 & D1 (600), D2 (600), D5 (1200), W6 (1200) & - \\
0.1 & 1521970 & D1 (1000), D5 (1200), W6 (1200) & P3 \\
0.12 & 1531891 & D1 (1200), D5 (1200), W6 (1200) & P2, P3 \\
0.15 & 1541321 & D1 (1000), D5 (1200), W6 (1200) & P2, P3 \\
0.2 & 1560047 & D1 (1000), D5 (1200), W6 (1200) & P1, P2, P3 \\
0.3 & 1597018 & D1 (1000), D5 (1200), W6 (1200) & P1, P2, P3 \\
0.4 & 1632347 & D2 (1200), D5 (1200), W6 (1200) & \\
\hline
\end{tabular}

TABLE 10: Comparison based on different demands of customers.

\begin{tabular}{lccc}
\hline Change rate in demand (\%) & Total cost (\$) & DC (Location size) & Environmental facility \\
\hline-20 & 1215203 & D1 (1200), D5 (1200) & P3 \\
-15 & 1292231 & D1 (1200), D5 (1200) & P3 \\
-10 & 1370389 & D1 (800), D5 (1200), W6 (1200) & P2, P3 \\
-5 & 1451982 & D1 (1000), D5 (1200), W6 (1200) & P2, P3 \\
0 & 1531891 & D1 (1200), D5 (1200), W6 (1200) & P2, P3 \\
+5 & 1611777 & D1 (600), D2 (1200), D5 (1200), W6 (1200) & P1, P3 \\
+10 & 1691455 & D1 (600), D2 (1200), D5 (1200), W6 (1200) & P1, P2, P3 \\
+15 & 1771053 & D1 (800), D2 (1200), D5 (1200), W6 (1200) & P1, P2, P3 \\
+20 & 1850660 & D1 (1000), D2 (1200), D5 (1200), W6 (1200) & P1, P2, P3 \\
+25 & 1930228 & D1 (1200), D2 (1200), D5 (1200), W6 (1200) & P1, P2, P3 \\
+30 & 2010062 & D1 (1200), D2 (1200), D5 (1200), W6 (1200) & P1, P2, P3 \\
+35 & 2090428 & D1 (1200), D2 (1200), D5 (1200), W6 (1200), W7 (600) & P1, P2, P3 \\
\hline 40 & 2170873 & D1 (1200), D2 (1200), D5 (1200), W6 (1200), W7 (800) & \\
\hline
\end{tabular}

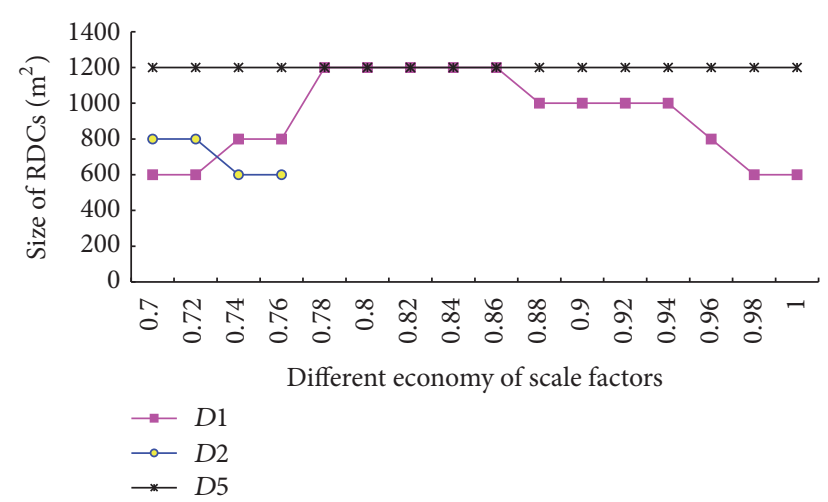

FIGURE 4: Optimal size of RDCs under different values of economies of scale parameter $\theta$.

increase from 0.7 to 0.72 , three RDCs are built, where sizes are 600,800 , and $1200 \mathrm{~m}^{2}$ at nodes 1,2 , and 5, respectively. The RDCs at nodes 1,2 , and 5 are selected again, while the range of the economies of scale factor is $[0.74,0.76]$; however, their sizes change into 800,600 , and $1200 \mathrm{~m}^{2}$, respectively. When $\theta$ is located at $[0.78,0.86]$, two RDCs at nodes 1 and 5 are built to satisfy the demands of customers. Both RDCs are $1200 \mathrm{~m}^{2}$. When the economies of scale parameter $\theta$ increase from 0.88 to 1 , the size of RDC remains at $1200 \mathrm{~m}^{2}$ at node 5 . However, the size of the RDC at node 1 decreases from $1000 \mathrm{~m}^{2}$ to $600 \mathrm{~m}^{2}$. Thus, the number of transported products increases

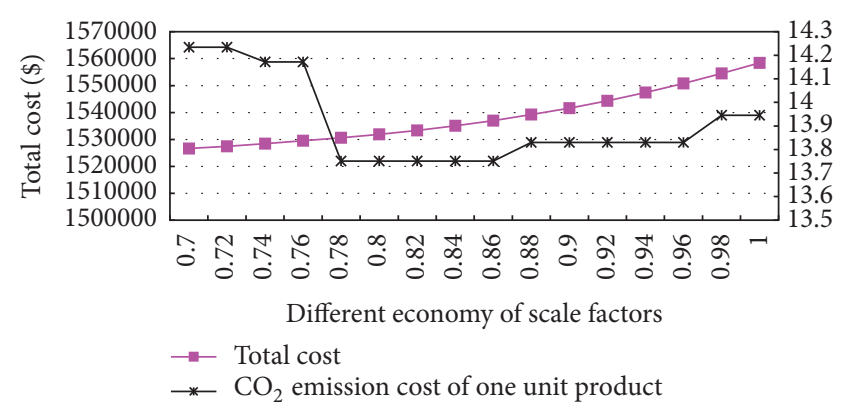

Figure 5: Total cost and $\mathrm{CO}_{2}$ emission cost of one unit product under different economies of scale parameter.

from plants to customers directly due to the decrease of fixed cost of the RDCs.

Figure 5 clearly shows that the total cost and $\mathrm{CO}_{2}$ emission cost of one unit product change with the increase in economies of scale parameter $\theta$. The total cost of supply chain increases gradually when the economy of scale factor increases. However, the $\mathrm{CO}_{2}$ emission cost of one unit product initially decreases and then increases. When the range of the economy of scale parameter is $[0.78,0.86]$, the $\mathrm{CO}_{2}$ emission cost of one unit product reaches minimum. This implies that the aggregate effect of RDCs is well achieved, while the range of economy of scale parameter falls in 
TABLE 11: Comparison based on different economies of scale parameter.

\begin{tabular}{|c|c|c|c|c|}
\hline $\begin{array}{l}\text { Economy of } \\
\text { scale parameter }\end{array}$ & Total cost $(\$)$ & DC (Location size) & $\begin{array}{c}\mathrm{CO}_{2} \text { emissions per unit } \\
\text { product } \\
(\$ / t)\end{array}$ & $\begin{array}{l}\text { Environmental } \\
\text { facility }\end{array}$ \\
\hline 0.7 & 1526641 & $\begin{array}{c}\text { D1 (600), D2 (800), } \\
\text { D5 (1200), W6 (1200) }\end{array}$ & 14.23414 & P3 \\
\hline 0.72 & 1527460 & $\begin{array}{c}\text { D1 (600), D2 (800), } \\
\text { D5 (1200), W6 (1200) }\end{array}$ & 14.23414 & P3 \\
\hline 0.74 & 1528397 & $\begin{array}{l}\text { D1 }(800), \text { D2 }(600), \\
\text { D5 (1200), W6 (1200) }\end{array}$ & 14.17196 & P3 \\
\hline 0.76 & 1529468 & $\begin{array}{l}\text { D1 (800), D2 (600), } \\
\text { D5 (1200), W6 (1200) }\end{array}$ & 14.17196 & P3 \\
\hline 0.78 & 1530623 & $\begin{array}{c}\text { D1 (1200), D5 (1200) } \\
\text { W6 (1200) }\end{array}$ & 13.75074 & P2 P3 \\
\hline 0.80 & 1531891 & $\begin{array}{c}\text { D1 (1200), D5 (1200) } \\
\text { W6 (1200) }\end{array}$ & 13.75074 & P2 P3 \\
\hline 0.82 & 1533352 & $\begin{array}{c}\text { D1 (1200), D5 (1200) } \\
\text { W6 (1200) }\end{array}$ & 13.75074 & P2 P3 \\
\hline 0.84 & 1535036 & $\begin{array}{c}\text { D1 (1200), D5 (1200) } \\
\text { W6 (1200) }\end{array}$ & 13.75074 & P2 P3 \\
\hline 0.86 & 1536976 & $\begin{array}{c}\text { D1 (1200), D5 (1200) } \\
\text { W6 (1200) }\end{array}$ & 13.75074 & P2 P3 \\
\hline 0.88 & 1539188 & $\begin{array}{c}\text { D1 (1000), D5 (1200), } \\
\text { W6 (1200) }\end{array}$ & 13.82949 & P2 P3 \\
\hline 0.90 & 1541564 & $\begin{array}{c}\text { D1 (1000), D5 (1200) } \\
\text { W6 (1200) }\end{array}$ & 13.82949 & P2 P3 \\
\hline 0.92 & 1544297 & $\begin{array}{c}\text { D1 (1000), D5 (1200), } \\
\text { W6 (1200) }\end{array}$ & 13.82949 & P2 P3 \\
\hline 0.94 & 1547442 & $\begin{array}{c}\text { D1 (1000), D5 (1200) } \\
\text { W6 (1200) }\end{array}$ & 13.82949 & P2 P3 \\
\hline 0.96 & 1550754 & $\begin{array}{c}\text { D1 (800), D5 (1200) } \\
\text { W6 (1200) }\end{array}$ & 13.89176 & P2 P3 \\
\hline 0.98 & 1554486 & $\begin{array}{c}\text { D1 (600), D5 (1200) } \\
\text { W6 (1200) }\end{array}$ & 13.94485 & P2 P3 \\
\hline 1.00 & 1558422 & $\begin{array}{c}\text { D1 (600), D5 (1200) } \\
\text { W6 (1200) }\end{array}$ & 13.94485 & P2 P3 \\
\hline
\end{tabular}

$[0.78,0.86]$, which will be useful in decreasing the $\mathrm{CO}_{2}$ emission per product.

3.4. Effects of the Number of RDCs on the Performance of Supply Chain Network. The effects of the number of RDCs on the performance of the supply chain network are discussed in this section. As shown in Figure 6, the total cost of the entire supply chain initially decreases slightly. Then, it increases with the decrease of the number of RDCs for a given ratio of carbon tax. This result implies that an optimal number of RDCs exist under some given logistics service level. Specifically, when the ratio of carbon tax range is $[0.05,0.1]$, considering minimizing total cost of supply chain, three RDCs should be built. Conversely, when the ratio of the carbon tax range is $[0.12,0.4]$, two RDCs should be built. Meanwhile, the total cost is directly proportional to the ratio of carbon tax. Larger carbon tax ratio leads to a larger total cost.

Given that decision-makers have decided on a suitable number of RDCs to be opened, having few RDCs does not mean low total cost. Increased carbon tax ratio encourages shorter routes, which leads to more RDCs being opened. In turn, the fixed costs of RDCs are higher, but the transportation cost is lower; whether the total cost of supply chain will increase or decrease depends on the tradeoff between the two costs. For example, when the carbon tax ratio is set at 0.12 and two RDCs are open, the total cost is less compared with the three RDCs. However, the manner in which the RDCs and $\mathrm{CO}_{2}$ emission can truly influence the total cost of the supply chain remains unclear. A real case will be demonstrated in the following section.

\section{Case Study}

In this section, we present the proposed model implemented in a real-life case-the network design of a green supply chain of an electric meter company in China. In this case, we provide some strategic guidance on the supply chain design considering environmental issues. We introduce a supply chain optimization model and conducted a case analysis. The 


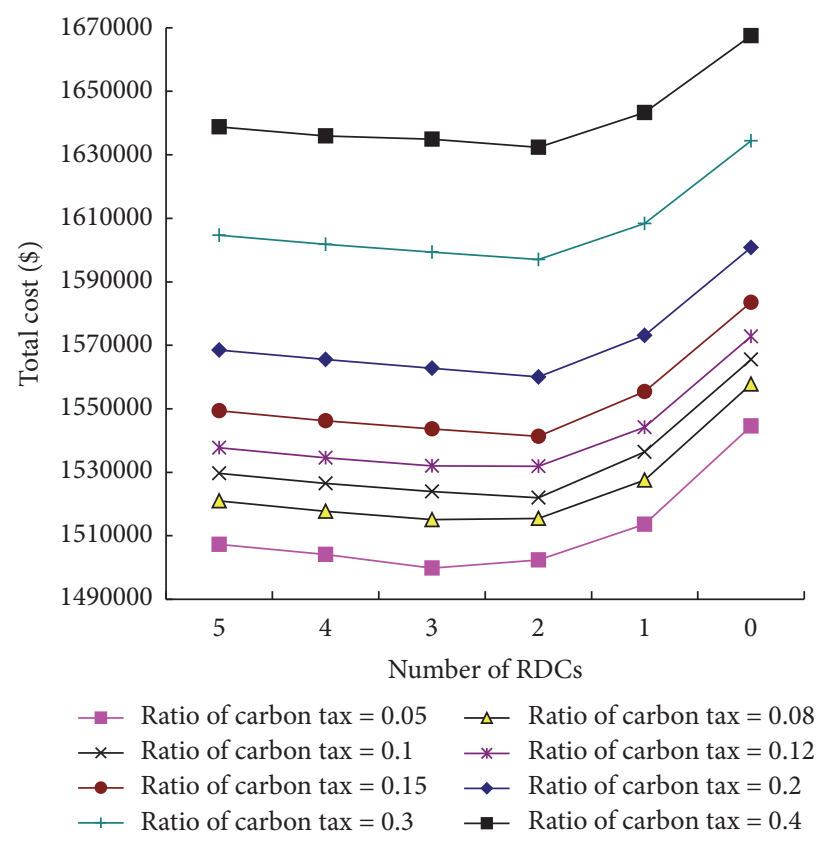

FIGURE 6: Effects of increasing the ratio of carbon tax.

base parameters are the same as the base scenario. Each arc is associated with different distances of different transport modes. The case study considers 1 plant in Changsha, 16 potential RDCs, and 50 customers in capital cities in China, and 6 alternative warehouses in Central, Eastern, South, Northwest, Northeast, and Southwest China, respectively. The data of customers' demand was originated from the report of the electric meter company in May 2011. The sample size is sufficient to represent the real supply chain network and is computationally manageable. In addition, the case is implemented by Lingol1.0. The result of the network design is presented in Figure 7.

In this case, we initially compare the computational cost with the actual cost. The computational cost is higher than the actual cost. This situation arises due to the increased cost of carbon emissions for the implementation of a constraint on freight transport emissions by policymakers who aim to reduce carbon emissions. As previously mentioned, decisionmakers of production companies encouraged reduced route length and increased environmental transport mode to minimize the total cost of the supply chain, resulting in opening more RDCs and renting more warehouses. Moreover, the use of environmental train and air transportation is increasing, because the increased $\mathrm{CO}_{2}$ emission taxation can drive decision-makers to choose greener transport modes. Furthermore, more RDCs are built or warehouses are rented due to the effects of economies of scale and $\mathrm{CO}_{2}$ emission taxes on the logistics network design. The percent of each component cost of entire supply chain is shown as Figure 8.

Figure 8 shows that the transportation cost $(42.95 \%)$ has the highest proportion in the total cost, followed by the transferring cost (38.63\%). Hence, finding the best combination of open RDCs and rented warehouses that minimize travel distance and achieve economies of scale is urgent. Designing

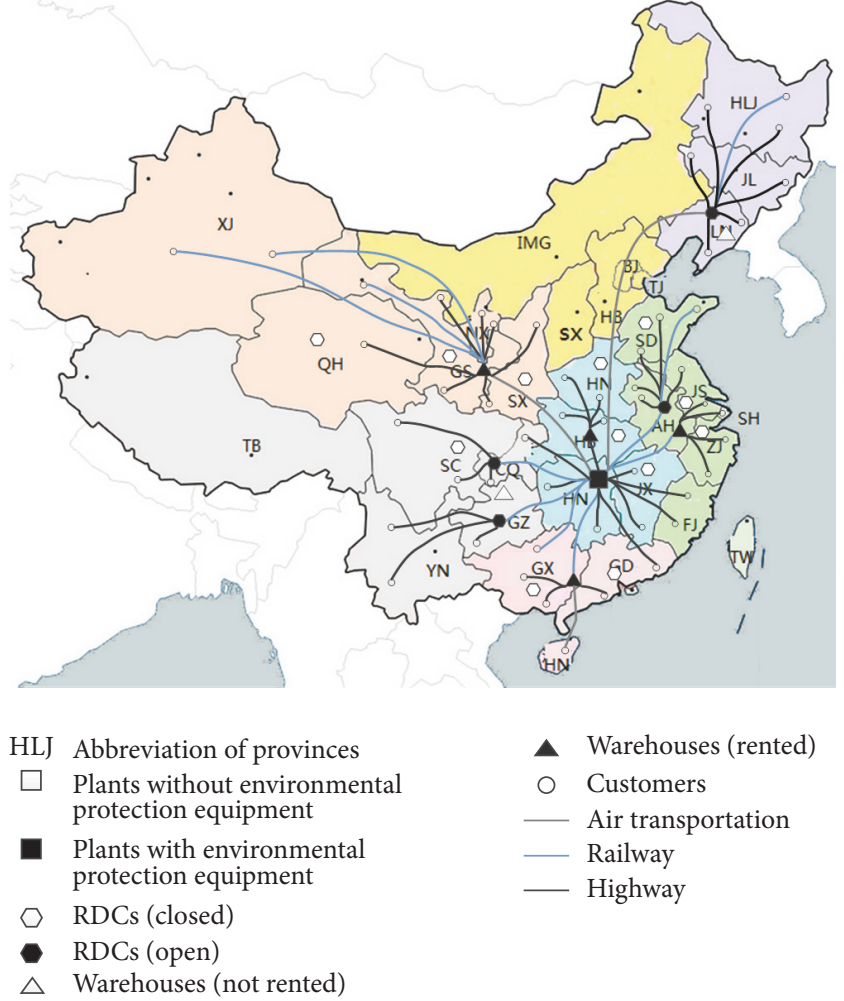

FIGURE 7: Supply chain network of an electric meter company in China.

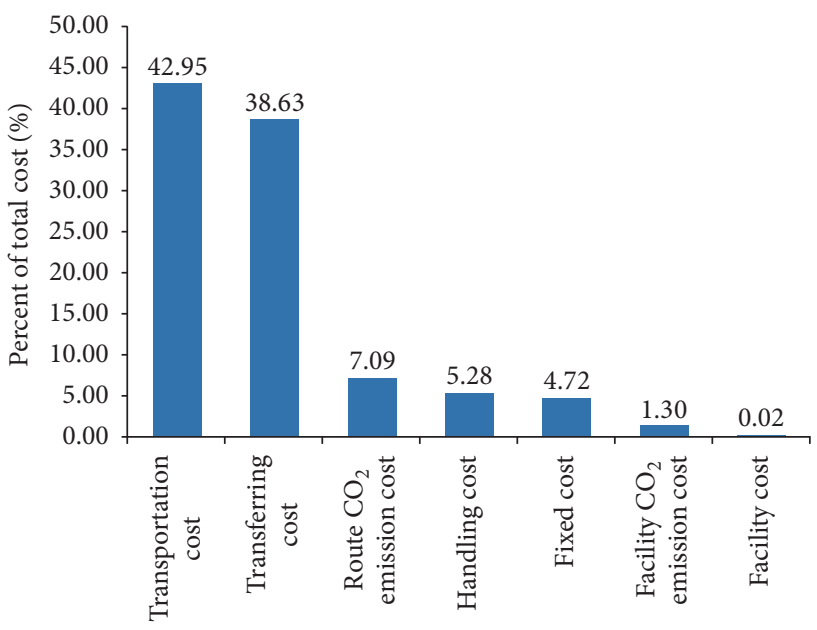

FIgURE 8: Total cost ratios in different parts of the supply chain.

an effective and efficient supply chain network can minimize the total cost. Route $\mathrm{CO}_{2}$ emission costs $(7.09 \%)$ contribute more than the facility $\mathrm{CO}_{2}$ emission cost $(1.3 \%)$ to the total $\mathrm{CO}_{2}$ emission cost. A more economical and ecological transport mode that addresses environmental concerns should be considered. The summation of the fixed cost $(4.72 \%)$ is attributed to building RDCs, and the handling cost (5.28\%) in open RDCs is lower than the transferring cost; thus, renting more warehouses is cheaper than building RDCs under current customers' demands. Although environmental 
facility cost $(0.02 \%)$ is the lowest proportion in the total cost, the cost of $\mathrm{CO}_{2}$ emission has significantly decreased. Investing more on the environment means a high level of environmental protection. Thus, companies should purchase more ecological facilities. Therefore, decreasing the travel distance between suppliers and customers by building suitable RDCs and renting reasonable warehouses is significant and will improve the added value in a real-life logistics chain of energy measurement equipment.

Remarkably, being responsible for $\mathrm{CO}_{2}$ emissions in the entire green supply chain indicates potential sustainable action plans. In this case, the total emission contributions are in two parts: product flow and facilities. This division is mainly due to the long travel distances from the suppliers to customers. Route emissions constitute nearly $80 \%$ of the total emissions. Conducting emission sources entirely presents the importance of distances between actors in terms of environmental impact.

Finally, we discussed and analyzed the managerial insights and policy implications as follows, which is based on the above numerical experiment and real-world case study.

(1) To design an effective green supply chain network, it is significant and more effective to integrate the RDCs location, investment of environmental facilities, and $\mathrm{CO}_{2}$ emission taxes charging measures.

The above green supply management initiative measures should be adopted according to the characteristic of products, logistics service requirements of customers, and the capacities of logistics supply. For the products with a lower manufacturing cost and quick responsible logistics service, a slower but green transport mode will be a better choice. Otherwise, a faster transport mode with high emission is the preferred one. Moreover, the combined transport mode should be used as much as possible to decrease the total $\mathrm{CO} 2$ emission of entire supply chain, which also needs to configure logistics transfer nodes (i.e., RDCs or warehouses). Moreover, it is also an effective way to invest environmental protection equipment or technology, so as to achieve the objective of decreasing the $\mathrm{CO}_{2}$ emissions of manufacturing process. In the longer run, environmental investment is useful for cutting down the total cost of supply chain.

(2) The economy of scale parameter has an important effect on the optimal number and size of the RDCs and $\mathrm{CO}_{2}$ emissions per unit shipment. The aggregate effect of RDCs is well achieved while the range of economy of scale parameter falls in $[0.78,0.86]$, which will help to decrease the $\mathrm{CO}_{2}$ emissions per product. Therefore, it is important for the operators to consider the effects of the economies of scale on the size of RDCs selection.

(3) It is necessary for government to set a rational $\mathrm{CO} 2$ emission tax ratio, which induces the manufacturers to develop the corresponding green supply chain.

The introduced $\mathrm{CO}_{2}$ emission tax changes the structure of the logistics service network, which will help to switch more green supply chain logistics service paths by the combined transport modes. Moreover, we can find that the number of RDCs will increase with increase of the carbon tax ratio. Therefore, the fixed cost of RDC becomes more, while the corresponding transport cost becomes less. The total cost of supply chain will decrease with increase of the $\mathrm{CO}_{2}$ emission tax ratio and then increase if the $\mathrm{CO}_{2}$ emission tax ratio is greater than the threshold value. In order to prevent a counterproductive outcome, the effective $\mathrm{CO}_{2}$ emission tax should be kept below the threshold. This implies that the rational carbon tax incentives can improve the performance of the green supply chain economically and environmentally.

\section{Conclusions and Future Studies}

In this study, we present a design problem for a supply chain network with carbon emission concerns, which aims to minimize the total costs considering $\mathrm{CO}_{2}$ emission taxes and the effects of the economies of scale. The total cost includes the fixed cost to purchase environmental protection equipment and establish RDCs or rent warehouses, the transportation cost to move products between nodes, and the cost of $\mathrm{CO}_{2}$ emissions generated from transportation and handling process. The supply chain network design model has an important application for the regional or global supply chain network design considering the environment.

The properties of the model are explored analytically and justified by a real-life case study-the network design of a green supply chain for an electric meter company in China. The following new insights and important findings are obtained. (1) The total cost and $\mathrm{CO}_{2}$ emission cost of one unit product change with the increase of the value of economies of scale parameter. (2) Different customers' demand significantly affects the location and size of RDCs. (3) The introduced $\mathrm{CO}_{2}$ emission taxes will change the structure of supply chain network, which may decrease $\mathrm{CO}_{2}$ emissions of per unit product.

It should be pointed out that although the numerical results that are presented in this paper can be explained logically, case studies on large and realistic logistics networks are necessary to further justify the findings of this paper and the performance of the proposed model. The proposed model can possibly be extended in several ways for future research. First, the time window can be considered while improving customer satisfaction. Second, other sources of emission and other sustainability key parameters can also be evaluated. Moreover, the design of an effective solution algorithm particularly for a large-scale logistics network should be addressed. Finally, the stochastic demand of customer can enhance its applicability in real-life scenarios.

\section{Notations}

\section{Parameters}

$i$ : Index for nodes, including suppliers, plant locations, RDCs, warehouses, and customers

$i, j$ : Index pairs referring to arcs from nodes $i$ to $j$

$m$ : Transport mode index

$\theta: \quad$ Economy of scale parameter of RDC

$M: \quad$ Set of candidate size of RDCs, $i \in C^{1}\left(\mathrm{~m}^{2}\right)$

$S$ : $\quad$ Set of arcs, $S=A B_{a} \cup B C_{a}^{1} \cup C^{1} D_{a} \cup B D_{a} \cup B C_{a}^{2} \cup C^{2} D_{a}$

$M_{i, j}$ : Set of transport modes (i.e., highways, railways, and air transportation) over $\operatorname{arc}(i, j) \in S$ 
$s_{i}: \quad$ Supply capacity of a product in a supplier, $i \in A$ (t)

$d_{i}$ : $\quad$ Demand of customer, $i \in D(\mathrm{t})$

$c_{i}^{v}: \quad$ Variable cost of a product unit in RDC, $i \in C^{1}$ $(\$ / \mathrm{t})$

$c_{i}: \quad$ Fixed cost in RDCs, $i \in C^{1}(\$)$

$c_{i}^{u}: \quad$ Unit construction cost of RDCs, $i \in C^{1}\left(\$ / \mathrm{m}^{2}\right)$

$c_{i}^{m}:$ Transfer cost of a product unit in a rented warehouse, $i \in C^{2}(\$ / t)$

$\operatorname{cap}_{i}^{w}$ : Capacity of the rented warehouses, $i \in C^{2}(\mathrm{t})$

$\operatorname{cap}_{i}^{c}$ : Capacity consumed by handling product unit in an RDC, $i \in C^{1}\left(\mathrm{~m}^{2} / \mathrm{t}\right)$

$c_{i, j}^{m}: \quad$ Transportation cost on $\operatorname{arc}(i, j) \in S$ with transport mode $m \in M(\$ / \mathrm{t}-\mathrm{km})$

$d_{i, j}^{m}: \quad$ Distance on $\operatorname{arc}(i, j) \in S$ with transport mode $m \in M(\mathrm{~km})$

$z$ : Ratio of carbon tax of per unit $\mathrm{CO}_{2}$ emission $(\$ / \mathrm{kg})$

$e_{i}^{h}: \quad \mathrm{CO}_{2}$ emissions from handling a product unit in a plant, $i \in B(\mathrm{~kg} / \mathrm{t})$

$c_{i}^{f}$ : $\quad$ Facility cost for purchasing environmental protection equipment or technology in a plant $i \in B(\$)$

$e_{i, j}^{m}: \quad \mathrm{CO}_{2}$ emission factor for transportation on $\operatorname{arc}(i, j) \in S$ with transport mode $m \in M$ $(\mathrm{kg} / \mathrm{t}-\mathrm{km})$

$r_{i}$ : $\quad$ Ratio of lowering $\mathrm{CO}_{2}$ emission in plant location $i \in B$. The level of environmental protection is higher corresponding to a heavier environmental investment but leads to lower $\mathrm{CO}_{2}$ emission.

\section{Decision Variables}

$\alpha_{i}$ : Binary variable is 1 , if an environment protection equipment or technology is purchased in plant location $i \in B$. Otherwise, binary variable is 0

$\beta_{i}$ : Binary variable is 1 , if an RDC is set up from potential RDCs set $i \in C^{1}$, or warehouse $i \in C^{2}$ is rented. Otherwise, binary variable is 0

$x_{i, j}^{m}$ : Flow quantities of product on $\operatorname{arc}(i, j) \in S$ with transport mode $m \in M(\mathrm{t})$

$y_{i}$ : Size of potential RDCs, $y_{i} \in M\left(\mathrm{~m}^{2}\right)$.

\section{Conflicts of Interest}

The authors declare that they have no conflicts of interest.

\section{Acknowledgments}

The work that is described in this paper was supported by Hunan Province Science and Technology Development Funds (no. 2015RS4045), Excellent Youth Project of Hunan Provincial Department of Education (no. 15B261), Graduate Education and Degree innovation Foundation of Central South University (no. 2014JGB36), and National Natural Science Foundation of China (No. 71672193 and 71271220).

\section{References}

[1] A. McKinnon, "Green logistics: the carbon agenda," LogForum, vol. 6 , no. 3, pp. 1-9, 2010.

[2] M. T. Melo, S. Nickel, and F. Saldanha-da-Gama, "Facility location and supply chain management-a review," European Journal of Operational Research, vol. 196, no. 2, pp. 401-412, 2009.

[3] H. Sadjady and H. Davoudpour, "Two-echelon, multi-commodity supply chain network design with mode selection, leadtimes and inventory costs," Computers and Operations Research, vol. 39, no. 7, pp. 1345-1354, 2012.

[4] Y. Wang, X. Ma, Y. Lao, and Y. Wang, "A fuzzy-based customer clustering approach with hierarchical structure for logistics network optimization," Expert Systems with Applications, vol. 41, no. 2, pp. 521-534, 2014.

[5] Y. Wang, X. Ma, M. Xu, Y. Liu, and Y. Wang, "Two-echelon logistics distribution region partitioning problem based on a hybrid particle swarm optimization-genetic algorithm," Expert Systems with Applications, vol. 42, no. 12, pp. 5019-5031, 2015.

[6] A. Sabzevari Zadeh, R. Sahraeian, and S. M. Homayouni, "A dynamic multi-commodity inventory and facility location problem in steel supply chain network design," The International Journal of Advanced Manufacturing Technology, vol. 70, no. 5-8, pp. 1267-1282, 2014.

[7] N. M. H. González, A. Á. Socarrás, and M. m. Pérez, "Determination of network configuration considering inventory cost in a supply chain," Journal of Applied Research and Technology, vol. 12, no. 4, pp. 674-683, 2014.

[8] A. Prakash, F. T. S. Chan, H. Liao, and S. G. Deshmukh, "Network optimization in supply chain: a KBGA approach," Decision Support Systems, vol. 52, no. 2, pp. 528-538, 2012.

[9] L. Benyoucef, X. Xie, and G. A. Tanonkou, "Supply chain network design with unreliable suppliers: a Lagrangian relaxationbased approach," International Journal of Production Research, vol. 51, no. 21, pp. 6435-6454, 2013.

[10] R. J. Merrick and J. H. Bookbinder, "Environmental assessment of shipment release policies," International Journal of Physical Distribution and Logistics Management, vol. 40, no. 10, pp. 748762, 2010.

[11] S. Benjaafar, J.-P. Gayon, and S. Tepe, "Optimal control of a production-inventory system with customer impatience," Operations Research Letters, vol. 38, no. 4, pp. 267-272, 2010.

[12] J. M. Cruz and D. Matsypura, "Supply chain networks with corporate social responsibility through integrated environmental decision-making," International Journal of Production Research, vol. 3, pp. 621-648, 2009.

[13] Y.-C. Tsao, "Distribution center network design under trade credits," Applied Mathematics and Computation, vol. 222, pp. 356-364, 2013.

[14] Z. C. Qin, "Research on the methods of logistics systems planning in distribution center," Applied Mechanics and Materials, vol. 687-691, pp. 4573-4576, 2014.

[15] M. F. Gorman and T. Ball, "Practice summary: chemstation embarks on a new approach to customer delivery," Interfaces, vol. 45, no. 6, pp. 567-571, 2015.

[16] K. Baumgartner, A. Fuetterer, and U. W. Thonemann, "Supply chain design considering economies of scale and transport frequencies," European Journal of Operational Research, vol. 218, no. 3, pp. 789-800, 2012.

[17] S. Saranwong and C. Likasiri, "Product distribution via a bilevel programming approach: algorithms and a case study in 
municipal waste system," Expert Systems with Applications, vol. 44, pp. 78-91, 2016.

[18] J. V. D. Broek, P. Schütz, L. Stougie, and A. Tomasgard, "Location of slaughterhouses under economies of scale," European Journal of Operational Research, vol. 175, no. 2, pp. 740-750, 2006.

[19] B. Fleischmann, "Designing distribution systems with transport economies of scale," European Journal of Operational Research, vol. 70, no. 1, pp. 31-42, 1993.

[20] Z.-C. Li, W. H. Lam, and S. C. K. Wong, "Optimization of number of operators and allocation of new lines in an oligopolistic transit market," Networks and Spatial Economics, vol. 12, no. 1, pp. 1-20, 2012.

[21] A. Beresford, S. Pettit, and Y. Liu, "Multimodal supply chains: iron ore from Australia to China," Supply Chain Management, vol. 16, no. 1, pp. 32-42, 2011.

[22] D. M. Z. Islam, J. Dinwoodie, and M. Roe, "Towards supply chain integration through multimodal transport in developing economies: the case of Bangladesh," Maritime Economics and Logistics, vol. 7, no. 4, pp. 382-399, 2005.

[23] J. P. P. Vilko and J. M. Hallikas, "Risk assessment in multimodal supply chains," International Journal of Production Economics, vol. 140, no. 2, pp. 586-595, 2012.

[24] F. Xie, Y. X. Huang, and S. Eksioglu, "Integrating multimodal transport into cellulosic biofuel supply chain design under feedstock seasonality with a case study based on California," Bioresource Technology, vol. 152, pp. 15-23, 2014.

[25] P. Sitek and J. Wikarek, "Cost optimization of supply chain with multimodal transport," in Proceedings of the Federated Conference on Computer Science and Information Systems, pp. 1111-1118, 2012.

[26] P. Sitek and J. Wikarek, "A hybrid approach to modeling and optimization for supply chain management with multimodal transport," in Proceedings of the International Conference on Methods and MODELS in Automation and Robotics, pp. 777782, 2013.

[27] A. Tognetti, P. T. Grosse-Ruyken, and S. M. Wagner, "Green supply chain network optimization and the trade-off between environmental and economic objectives," International Journal of Production Economics, vol. 170, pp. 385-392, 2015.

[28] S. Elhedhli and R. Merrick, "Green supply chain network design to reduce carbon emissions," Transportation Research Part D: Transport and Environment, vol. 17, no. 5, pp. 370-379, 2012.

[29] M. Wang, K. Liu, T.-M. Choi, and X. Yue, "Effects of carbon emission taxes on transportation mode selections and social welfare," IEEE Transactions on Systems, Man, and Cybernetics: Systems, vol. 45, no. 11, pp. 1413-1423, 2015.

[30] A. C. McKinnon and M. I. Piecyk, "Measurement of $\mathrm{CO}_{2}$ emissions from road freight transport: a review of UK experience," Energy Policy, vol. 37, no. 10, pp. 3733-3742, 2009.

[31] F. Wang, X. Lai, and N. Shi, "A multi-objective optimization for green supply chain network design," Decision Support Systems, vol. 51, no. 2, pp. 262-269, 2011.

[32] I. Harris, C. L. Mumford, and M. M. Naim, "An evolutionary biobjective approach to the capacitated facility location problem with cost and $\mathrm{CO}_{2}$ emissions," in Proceedings of the Genetic and Evolutionary Computation Conference (GECCO '11), pp. 687704, DBLP, Dublin, Ireland, July 2011.

[33] I. Harris, C. L. Mumford, and M. M. Naim, "A hybrid multiobjective approach to capacitated facility location with flexible store allocation for green logistics modeling," Transportation Research Part E: Logistics and Transportation Review, vol. 66, pp. 1-22, 2014.
[34] M. Soysal, J. M. Bloemhof-Ruwaard, and J. G. A. J. van der Vorst, "Modelling food logistics networks with emission considerations: the case of an international beef supply chain," International Journal of Production Economics, vol. 152, pp. 5770, 2014.

[35] D. Zhang, R. Eglese, and S. Li, "Optimal location and size of logistics parks in a regional logistics network with economies of scale and $\mathrm{CO}_{2}$ emission taxes," Transport, 2015.

[36] S. Benjaafar, Y. Li, and M. Daskin, "Carbon footprint and the management of supply chains: insights from simple models," IEEE Transactions on Automation Science and Engineering, vol. 10, no. 1, pp. 99-116, 2013.

[37] K. M. R. Hoen, T. Tan, J. C. Fransoo, and G. J. van Houtum, Effect of Carbon Emission Regulations on Transport Mode Selection in Supply Chains, Eindhoven University of Technology, Eindhoven, The Netherlands, 2010.

[38] K. M. R. Hoen, T. Tan, J. C. Fransoo, and G.-J. Van Houtum, "Switching transport modes to meet voluntary carbon emission targets," Transportation Science, vol. 48, no. 4, pp. 592-608, 2014.

[39] K. M. R. Hoen, T. Tan, J. C. Fransoo, and G. J. Van Houtum, "Effect of carbon emission regulations on transport mode selection under stochastic demand," Flexible Services and Manufacturing Journal, vol. 26, no. 1-2, pp. 170-195, 2014.

[40] D. Sheng, Z.-C. Li, X. Fu, and D. Gillen, "Modeling the effects of unilateral and uniform emission regulations under shipping company and port competition," Transportation Research Part E: Logistics and Transportation Review, vol. 101, pp. 99-114, 2017. 


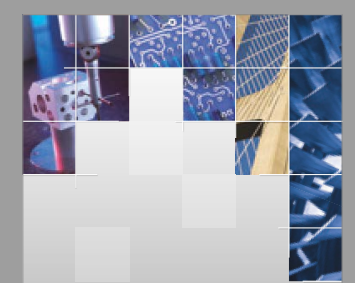

\section{Enfincering}
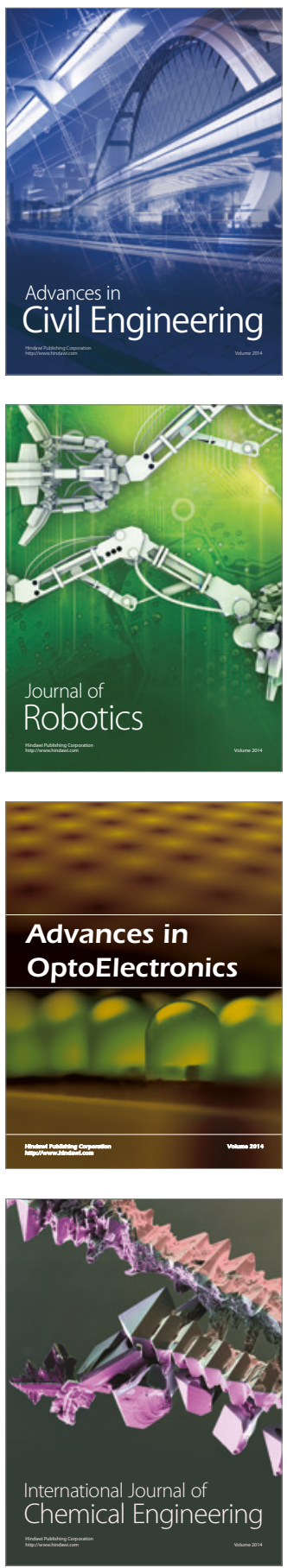

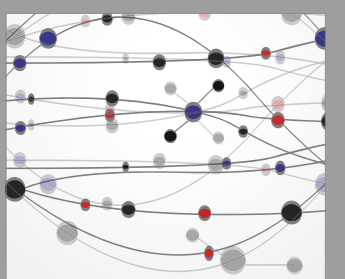

The Scientific World Journal

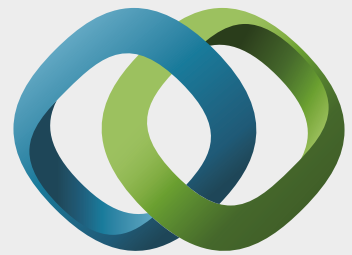

\section{Hindawi}

Submit your manuscripts at

https://www.hindawi.com
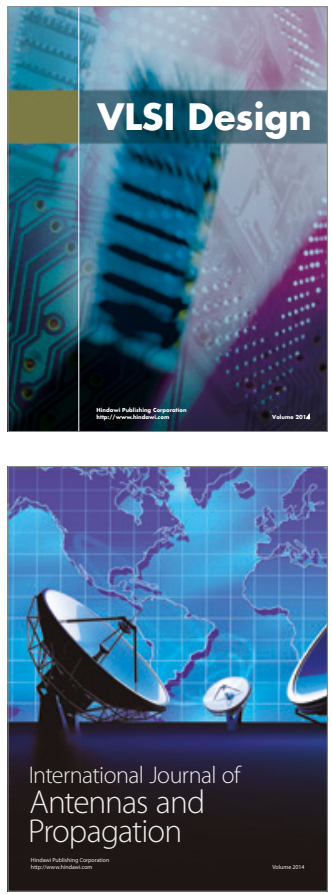

\section{Rotating}

Machinery
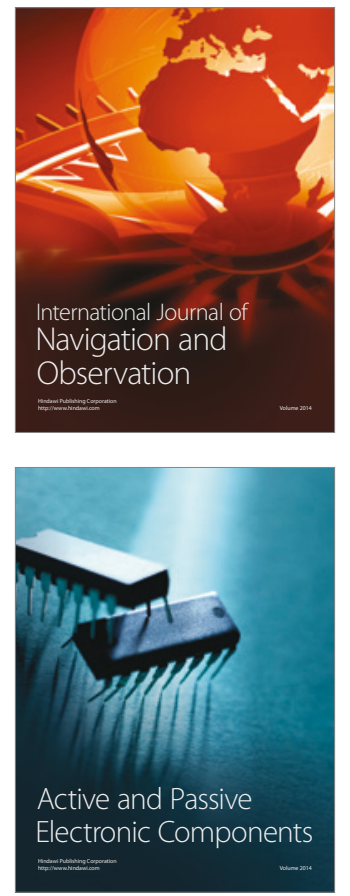
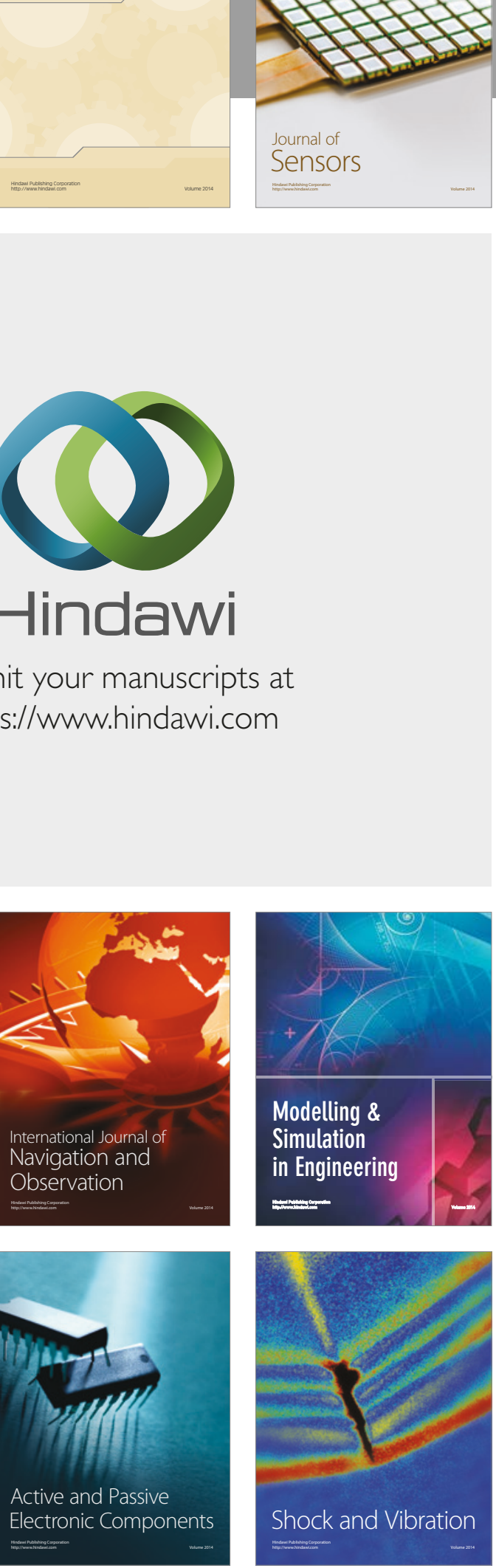
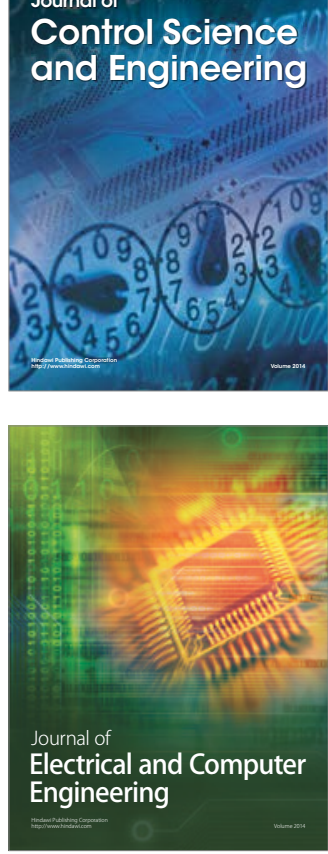

Distributed

Journal of

Control Science

and Engineering
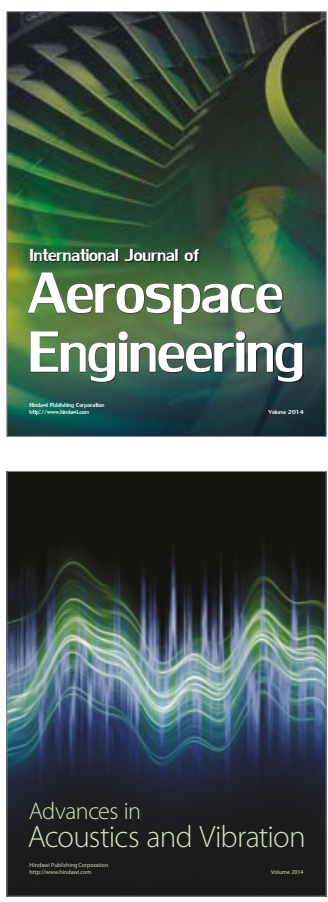

Sensor Networks 